\title{
Combined anti-arrhythmic therapy with class 1 and class 3 drugs
}

\author{
M.A. James, ${ }^{*}$ P. Papouchado and J.V. Jones \\ Department of Cardiology, Bristol Royal Infirmary, Bristol BS2 8HW, UK.
}

\begin{abstract}
Summary: This study was designed to investigate the differences in efficacy between 3 different combinations of amiodarone and a class 1 anti-arrhythmic drug (one from each class). The purpose was to determine whether the known differing electrophysiological properties of class 1 drugs result in any particular one making a superior combination with the class 3 drug amiodarone. Eight patients were studied in a randomized single blind cross-over trial. Amiodarone and flecainide proved to be the superior combination producing a significantly greater reduction in mean ectopic counts/24 hours than the amiodarone/mexilitene combination $(1,286$ vs 3,$243 ; P<0.05)$ or the amiodarone/disopyramide combination (3,795; $P<\mathbf{0 . 0 5})$. All 3 combinations reduced mean ectopic counts from the baseline value $(8,729)$, but this was only significant for amiodarone/flecainide $(P<0.01)$ and amiodarone/ mexilitene $(P<0.05)$. In addition the amiodarone/flecainide combination produced a significant reduction in complex forms of arrhythmia with ventricular tachycardia abolished in all cases, which was not achieved by any other combination.
\end{abstract}

\section{Introduction}

It is probable that combinations of anti-arrhythmic drug therapy will be tried for patients with refractory, life threatening ventricular arrhythmias. The combination of a class 1 with a class 3 agent (Vaughan Williams classification ${ }^{1}$ ) is particularly attractive since these act principally on different phases of the action potential; hence additive effects from their combined use might be anticipated. The electrophysiological characteristics that constitute an effective combination are, however, unknown. Sub-classification of class 1 agents reveals groups of drugs with differing effects on the action potential. Thus whilst all class 1 drugs prolong phase 0 of the action potential diverse effects on the repolarization phase ensure that the 3 sub-categories have different effects on the overall action potential duration. ${ }^{2}$

Prolongation of phase 0 alone would tend to slightly lengthen the action potential; however, class la drugs additionally lengthen the repolarization phase whilst class $1 \mathrm{~b}$ drugs shorten it and class $1 \mathrm{c}$ drugs have no effect on repolarization. The nett effect is that class la drugs lengthen and $1 \mathrm{~b}$ drugs shorten whilst $1 \mathrm{c}$ drugs have only a very small effect on the action potential duration. These actions are reflected by changes in the surface electrocardiogram such that class la drugs prolong QT and JT intervals, class lc drugs prolong

Correspondence: M.A. James, M.R.C.P.

Accepted: 3 March 1989

*Supported by the Wellcome Trust. the QT interval but without altering the JT interval and class $1 \mathrm{~b}$ drugs shorten both. Since both class $1 \mathrm{a}$ and class 3 drugs prolong repolarization, and hence the QT interval, it has been suggested that their combined use might be dangerous, ${ }^{3,4}$ causing excessive QT prolongation with its coincident risk of ventricular arrhythmias. On the other hand it might be anticipated that class $1 \mathrm{~b}$ drugs which shorten the QT interval may help to protect against class 3 induced pro-arrhythmic effects. However, it is now known that the antiarrhythmic effects of amiodarone are dependent upon QT prolongation. ${ }^{5,6}$ It is thus possible that class 1a drugs might enhance class 3 anti-arrhythmic effects whilst class $1 \mathrm{~b}$ drugs might antagonize them. Alternatively class $1 \mathrm{c}$ drugs, by not interfering with repolarization, may have the least chance of adversely interacting with class 3 anti-arrhythmic activity. $\mathrm{We}^{7}$ and other authors ${ }^{8-10}$ have reported the successful use of various combinations of class 1 and class 3 drugs but the possibility that specific types of combinations may possess relative advantages or disadvantages has not been reported previously. The purpose of this study was to investigate which, if any, of these class 1 sub-groups, with their known electrophysiological differences, might be most effectively used in combination with the class 3 drug amiodarone.

\section{Patients and methods}

Eight patients were recruited, their mean age was 58 years and 5 were male. Seven of the 8 patients had

(C) The Fellowship of Postgraduate Medicine, 1989 
experienced ventricular tachycardia, associated in 5 cases with syncope. All patients were receiving amiodarone at entry to the study and most had received a variety of class 1 drugs previously without success. Full details are given in Table I. The study was approved by the hospital ethics committee and informed consent was obtained.

Patients were recruited to the study from among those found to have incomplete control of arrhythmia whilst on amiodarone therapy alone; for the purpose of the study this was defined as those patients with more than 500 ventricular ectopics during 24 hour ambulatory electrocardiography. Patients were excluded if they had moderate cardiac failure (requiring more than $40 \mathrm{mg}$ frusemide or equivalent daily) or were known to be intolerant of one of the study drugs.

The study was performed by comparing the effects of combinations of amiodarone (a class 3 drug) with a representative drug from each of the class 1 subgroups. These were: disopyramide (1a), mexilitene (1b) and flecainide (1c). Dosages employed in the study consisted of: amiodarone $200 \mathrm{mg}$ daily, disopyramide sustained release $250 \mathrm{mg}$, mexilitene sustained release $360 \mathrm{mg}$ and flecainide $100 \mathrm{mg}$ each twice a day. These doses were chosen because they were approximately equivalent sized doses of each class 1 drug and allowed the number of tablets daily to remain the same for each study period. The dose of amiodarone chosen $(200 \mathrm{mg}$ ) was selected as the most widely used maintenance dosage. Treatments were administered in a randomized cross-over fashion with treatment effects monitored by $\mathbf{4 8}$ hour ambulatory electrocardiography which was performed at entry to the study whilst on amiodarone alone (baseline) and at the end of each treatment period of 2 weeks. Thirty six to 48 hours after the initiation of each combination treatment patients were seen for repeat 12 lead electro- cardiography to check that no toxic effects had developed. At the end of the study patients were also tried alone on the class 1 drug that had comprised part of the most successful combination, unless they had already received this drug without success. In view of the slow clearance of amiodarone, effects of withdrawal were monitored over 5-6 months, the dose of amiodarone being initially reduced to $100 \mathrm{mg}$ daily and if arrhythmia control remained good after 2-3 months, stopped altogether with the patient monitored for a further 3 months.

Ambulatory electrocardiography was performed using Reynolds Tracker recorders and a Pathfinder III analyser. Analysis was visually assisted in order to maintain accuracy. Total ectopic counts and frequency of complex events were recorded. Complex events were defined as any or all of the following: multifocal ectopics, couplets, salvoes or ventricular tachycardia (VT) - where VT was defined as any run of 3 or more ectopics and salvoes were defined as any group of 2 or more ectopics that did not appear to constitute VT or couplets, for instance ectopics from different foci. In view of the known variability of ectopic counts during successive 24 hour periods the results were also analysed according to the criteria proposed by Morganroth et al. ${ }^{11}$ which requires that drug effects can only be considered to be significant if they produce a greater than $83 \%$ reduction in ectopics.

Statistical analysis was by Wilcoxon's paired signed rank test, McNemar's test and Fisher's exact probability test.

\section{Results}

A complete set of results was available in only 6 patients but the data from the other 2 patients are also

Table I Patients

\begin{tabular}{|c|c|c|c|c|c|c|c|}
\hline & Age & Sex & Heart disease & Concurrent therapy & Arrhythmia & Syncope & Previous treatment \\
\hline 1 & 65 & $\mathbf{M}$ & Hypertensive/ischaemic & Diuretics, nitrates & VT, Complex VEB & Yes & Amiodarone \\
\hline 2 & 39 & $\mathbf{F}$ & Mitral valve prolapse & Nil & VT, Complex VEB & Yes & $\begin{array}{l}\text { Disopyramide, mexilitene, } \\
\text { amiodarone, tocainide, } \\
\text { flecainide }\end{array}$ \\
\hline 3 & 67 & $\mathbf{M}$ & Ischaemic & Nil & VT, Complex VEB & Yes & $\begin{array}{l}\text { Mexilitene, disopyramide, } \\
\text { atenolol, amiodarone }\end{array}$ \\
\hline 4 & 69 & $\mathbf{M}$ & Ischaemic & Diuretics & Complex VEB & No & Amiodarone \\
\hline 5 & 50 & $\mathbf{F}$ & Unknown & Nil & VT, Complex VEB & Yes & $\begin{array}{l}\text { Propranolol, procainamide, } \\
\text { disopyramide, amiodarone, } \\
\text { tocainide }\end{array}$ \\
\hline 6 & 64 & $\mathbf{F}$ & Ischaemic & Diuretics & VT & No & Amiodarone \\
\hline 7 & 46 & $\mathbf{M}$ & Hypertensive/ischaemic & Warfarin & VT, Complex VEB & No & $\begin{array}{l}\text { Disopyramide, amiodarone } \\
\text { flecainide }\end{array}$ \\
\hline 8 & 64 & $\mathbf{M}$ & Cardiomyopathy & Nil & VT, Complex VEB & Yes & Mexilitene, amiodarone \\
\hline
\end{tabular}

$\mathrm{VT}=$ ventricular tachycardia $\mathbf{V E B}=$ ventricular ectopic beats. 
presented, providing useful information on toxicity and electrophysiological effects.

The results showed that amiodarone and flecainide was significantly better than any other treatment in reducing ectopic activity, (Table II and Figure 1) whilst amiodarone and mexilitene was significantly better than both baseline (amiodarone alone) and the amiodarone/disopyramide combination. Amiodarone and flecainide also caused a significant reduction in complex events compared with baseline (Table III). When analysed by the method of Morganroth, ${ }^{11}$ amiodarone and flecainide again produced the best results, producing a significant improvement in ectopic counts in $5 / 6$ patients (8/11 tapes), whilst amiodarone and mexilitene produced a significant improvement in $4 / 6$ patients (6/11 tapes) and amiodarone and disopyramide produced a significant improvement in only $2 / 6$ patients (3/11 tapes).

Attempting to withdraw amiodarone from the successful combination caused a deterioration in all cases, not just in terms of ectopic counts but in complex events as well (Table IV). In view of this deterioration in response the amiodarone could not be stopped in 3 patients and the results are presented for

Table II Ectopic counts

\begin{tabular}{|c|c|c|c|c|c|c|c|}
\hline \multirow[t]{2}{*}{ Patient } & \multirow{2}{*}{$\begin{array}{c}\text { Baseline } \\
\text { (amiodarone) } \\
a\end{array}$} & \multicolumn{2}{|c|}{$\stackrel{+}{\text { Disopyramide }}$} & \multicolumn{2}{|c|}{$\begin{array}{l}+ \\
\text { Mexilitene }\end{array}$} & \multicolumn{2}{|c|}{$\stackrel{+}{\text { Flecainide }}$} \\
\hline & & $a$ & $b$ & $a$ & $b$ & $a$ & $b$ \\
\hline 2 & $\begin{array}{l}23,186 \\
10,751\end{array}$ & $\begin{array}{c}19,174 \\
-\end{array}$ & $\begin{array}{c}82.7 \\
-\end{array}$ & $\begin{array}{l}16,999 \\
13,924\end{array}$ & $\begin{array}{r}73.3 \\
129.5\end{array}$ & $\begin{array}{l}6,873 \\
5,672\end{array}$ & $\begin{array}{l}29.6 \\
52.8\end{array}$ \\
\hline 3 & $\begin{array}{l}22,252 \\
20,479\end{array}$ & $\begin{array}{l}3,661 \\
4,698\end{array}$ & $\begin{array}{l}16.4 \\
22.9\end{array}$ & $\begin{array}{l}872 \\
836\end{array}$ & $\begin{array}{l}3.9 \\
4.1\end{array}$ & $\begin{array}{l}51 \\
41\end{array}$ & $\begin{array}{l}0.2 \\
0.2\end{array}$ \\
\hline 4 & $\begin{array}{r}1,409 \\
913\end{array}$ & $\begin{array}{l}1,873 \\
1,246\end{array}$ & $\begin{array}{l}132.9 \\
136.5\end{array}$ & $\begin{array}{r}974 \\
1,518\end{array}$ & $\begin{array}{r}69.1 \\
166.3\end{array}$ & $\begin{array}{l}86 \\
28\end{array}$ & $\begin{array}{l}6.1 \\
3.1\end{array}$ \\
\hline 5 & $\begin{array}{r}2,843 \\
709\end{array}$ & $\begin{array}{l}7,826 \\
2840\end{array}$ & 256.3 & $\begin{array}{r}1 \\
157\end{array}$ & 0.03 & 1 & 0.03 \\
\hline 7 & $\begin{array}{r}7,355 \\
\end{array}$ & $\begin{array}{r}2,840 \\
123\end{array}$ & $\begin{array}{r}400.5 \\
1.7\end{array}$ & $\begin{array}{l}157 \\
241\end{array}$ & $\begin{array}{r}22.1 \\
3.3\end{array}$ & $\begin{array}{r}20 \\
261\end{array}$ & $\begin{array}{l}2.8 \\
3.5\end{array}$ \\
\hline 8 & $\begin{array}{r}12,973 \\
841 \\
1,042\end{array}$ & $\begin{array}{r}13 \\
323 \\
512\end{array}$ & $\begin{array}{r}0.7 \\
38.4 \\
49.1\end{array}$ & $\begin{array}{r}136 \\
21 \\
-\quad\end{array}$ & $\begin{array}{l}1.0 \\
2.5 \\
-\end{array}$ & $\begin{array}{l}- \\
946 \\
169\end{array}$ & $\begin{array}{r}- \\
112.5 \\
16.2\end{array}$ \\
\hline Total & 104,753 & 41,749 & & 35,679 & & 14,148 & \\
\hline $\begin{array}{l}\text { Mean } \\
\text { Median }\end{array}$ & $\begin{array}{l}8,729 \\
5,100\end{array}$ & $\begin{array}{l}3,795 \\
2,840\end{array}$ & $\begin{array}{r}103.4 \\
49.1\end{array}$ & $\begin{array}{r}3,243 \\
836\end{array}$ & $\begin{array}{r}35.1 \\
4.1\end{array}$ & $\begin{array}{r}1,286 \\
86\end{array}$ & $\begin{array}{r}20.6 \\
3.5\end{array}$ \\
\hline $6^{*}$ & $\begin{array}{r}15,825 \\
0\end{array}$ & $\begin{array}{l}0 \\
0\end{array}$ & $\begin{array}{l}0 \\
0\end{array}$ & $\begin{array}{l}- \\
-\end{array}$ & $\begin{array}{l}- \\
-\end{array}$ & $\begin{array}{l}0 \\
0\end{array}$ & $\begin{array}{l}0 \\
0\end{array}$ \\
\hline
\end{tabular}

$a=$ ectopic count $/ 24$ hours; $b=$ ectopic count expressed as a $\%$ of baseline; ${ }^{*}=$ this patient excluded from analysis (see text).

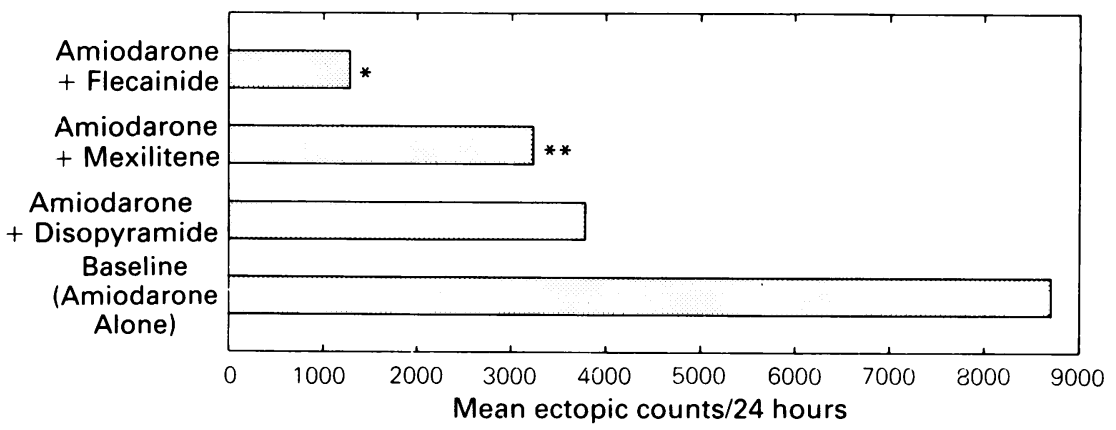

Figure 1 Mean ectopic counts per 24 hours during each treatment. Statistical analysis: Wilcoxon paired signed rank test. * vs Baseline $P<0.01 ;{ }^{*}$ vs A/D $P<0.05 ;{ }^{*}$ vs A/M $P<0.05 ;{ }^{* *}$ vs Baseline $P<0.05 ;{ }^{* *}$ vs A/D $P<0.05$. A/D amiodarone and disopyramide combined treatment; $A / M$ - amiodarone and mexilitene combined treatment. 
Table III Complex arrhythmia

\begin{tabular}{|c|c|c|c|c|}
\hline \multirow[b]{2}{*}{ Arrhythmia } & \multirow[b]{2}{*}{$\begin{array}{l}\text { Amiodarone } \\
\text { alone }\end{array}$} & \multicolumn{2}{|c|}{ Drug combination } & \multirow[b]{2}{*}{$\underset{\text { Flecainide }}{+}$} \\
\hline & & $\stackrel{+}{+} \underset{\text { Disopyramide }}{\stackrel{+}{n^{2}}}$ & $\stackrel{+}{+}$ & \\
\hline $\begin{array}{l}\text { Ventricular } \\
\text { tachycardia }\end{array}$ & 3 & 2 & 2 & 0 \\
\hline $\begin{array}{l}\text { Salvoes or } \\
\text { couplets }\end{array}$ & 5 & 5 & 3 & $1^{* *}$ \\
\hline $\begin{array}{c}\text { Multifocal } \\
\text { ectopics }\end{array}$ & 4 & 4 & 4 & 4 \\
\hline $\begin{array}{l}\text { Total } \\
\text { (all complex) } \\
\text { events }\end{array}$ & 12 & 11 & 9 & $5^{*}$ \\
\hline
\end{tabular}

Figures represent number of patients in each category.

${ }^{*} P<0.05$ amiodarone and flecainide $v s$ amiodarone (McNemar); ${ }^{* *} P<0.04$ amiodarone and flecainide $v s$ amiodarone (Fisher's exact test).

Table IV Efficacy of class 1 drug from best combination when used alone

\begin{tabular}{|c|c|c|c|c|c|c|c|c|c|c|c|c|c|}
\hline & & aselin & & & Clas & drug & lone & & & Best C & nbina & & \\
\hline & $V E B / 24 h$ & $V T$ & $S / C$ & $M$ & $V E B / 24 h$ & $V T$ & $S / C$ & $M$ & $V E B / 24 h$ & $V T$ & $S / C$ & $M$ & Drugs \\
\hline 2 & $\begin{array}{l}23,186 \\
10,751\end{array}$ & + & + & + & 15,146 & + & + & + & $\begin{array}{l}6,873 \\
5,672\end{array}$ & 0 & + & + & A/Flec \\
\hline 3 & $\begin{array}{l}22,252 \\
20,479\end{array}$ & 0 & + & + & $\begin{array}{r}* 7,102 \\
3,945\end{array}$ & 0 & 0 & 0 & $\begin{array}{l}872 \\
836\end{array}$ & 0 & 0 & 0 & A/Mex \\
\hline 4 & $\begin{array}{r}1,409 \\
913\end{array}$ & 0 & + & + & 3,615 & 0 & + & + & $\begin{array}{r}28 \\
86\end{array}$ & 0 & 0 & + & A/Flec \\
\hline 5 & $\begin{array}{r}2,843 \\
709\end{array}$ & + & + & 0 & 3,852 & + & + & 0 & $\begin{array}{r}1 \\
20\end{array}$ & 0 & 0 & 0 & A/Flec \\
\hline 7 & $\begin{array}{r}7,355 \\
12,973\end{array}$ & 0 & 0 & 0 & $* 261$ & 0 & 0 & 0 & $\begin{array}{r}123 \\
13\end{array}$ & 0 & 0 & 0 & A/Diso \\
\hline 8 & $\begin{array}{r}841 \\
1,042\end{array}$ & + & + & + & $* 7,520$ & 0 & + & + & $\begin{array}{l}946 \\
169\end{array}$ & 0 & 0 & 0 & A/Flec \\
\hline
\end{tabular}

*Amiodarone dosage reduced but not stopped altogether.

$\mathrm{VEB} / 24 \mathrm{~h}=$ ventricular ectopic beats per 24 hours; VT = ventricular tachycardia; $\mathrm{S} / \mathrm{C}=$ salvoes or couplets; $\mathrm{M}=$ multiform ectopics.

Drugs: $\mathrm{A}=$ amiodarone, Diso $=$ disopyramide, Flec $=$ flecainide, $\mathrm{Mex}=$ mexilitene .

Symbols: 0 = abnormality not demonstrated; + abnormality demonstrated.

the reduced dosage of amiodarone. In one case (patient 7) the decision not to stop amiodarone was purely clinical; the patient refused to drop his amiodarone dosage further after a deterioration in symptoms.

There was no evidence of pro-arrhythmic effects. Although in a few instances there was an increase in ectopic counts during a treatment period, the nature of the arrhythmia was not altered in these cases and the increase was not outside the anticipated normal daily variation. However, in one case there was a serious toxic effect on the electrocardiogram. This occurred during the amiodarone/flecainide combination and consisted of widening of the QRS complex $(0.21$ seconds) and prolongation of the QTc interval ( 0.68 seconds); this patient (number 1) also became nauseated on the mexilitene combination and was therefore withdrawn altogether. No other patient exhibited serious QRS or QT lengthening, although all 3 drugs exhibited the expected effects on QT intervals, significant prolongation occurring with both the disopyramide/amiodarone and flecainide/amiodarone combinations (Table V).

One other patient was excluded from the final analysis (number 6); although her first baseline 24 hour tape had shown a lot of ectopic activity this 
Table $\mathbf{V}$ Effect on QT intervals

\begin{tabular}{|c|c|c|c|c|}
\hline & \multicolumn{4}{|c|}{$Q T c$ intervals (seconds) } \\
\hline & $\begin{array}{c}\text { Amiodarone } \\
\text { alone }\end{array}$ & 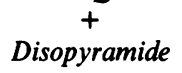 & $\stackrel{+}{+}$ & $\stackrel{+}{+}$ \\
\hline 1 & 0.46 & & 0.47 & 0.68 \\
\hline 2 & 0.42 & 0.48 & 0.49 & 0.49 \\
\hline 3 & 0.41 & 0.44 & 0.37 & 0.44 \\
\hline 4 & 0.43 & 0.42 & 0.39 & 0.44 \\
\hline 5 & 0.43 & 0.47 & 0.45 & 0.45 \\
\hline 6 & 0.44 & 0.50 & & 0.47 \\
\hline 7 & 0.40 & 0.43 & 0.37 & 0.42 \\
\hline 8 & 0.46 & 0.49 & 0.45 & 0.48 \\
\hline Mean & 0.431 & $0.461^{*}$ & 0.427 & $\mathrm{a} 0.456^{* *}$ \\
\hline
\end{tabular}

a - excluding value for 1 ( 0.484 including this).

${ }^{*} P<0.05$ compared with baseline; ${ }^{* *} P<0.01$ compared with baseline.

had occurred mostly as ventricular tachycardia, the second baseline tape and all subsequent tapes showed no ectopic activity at all, it was therefore assumed that her arrhythmia consisted of paroxysmal ventricular tachycardia alone and subsequent treatment effects could not therefore be reliably assessed. This patient was also unable to tolerate the amiodarone and mexilitene combination because of nausea. The remaining 6 patients had few complaints of side effects which were generally mild and predictable; 3 experienced dry mouth on disopyramide and 1 on flecainide, 2 complained of nausea on mexilitene and 1 complained of tiredness on flecainide.

There was a technical failure during 3 of the 24 hour tape recordings leading to loss of data for these three 24 hour periods.

\section{Discussion}

There are reports of the successful treatment of ventricular arrhythmia by combination therapy employing at least one drug from each of the three class 1 sub-groups in combination with amiodarone. ${ }^{7-9}$ In view of the different electrophysiological properties of each of these sub-groups it is possible that drugs from one particular sub-group may make a better combination with class 3 drugs than the others.

This study has shown that combined therapy with class 1 and class 3 anti-arrhythmic drugs can be extremely effective and this was confirmed by checking that the patient could not have been equally well controlled with the class 1 drug on its own. They had, of course, all been inadequately controlled by amiodarone alone. However, the results also show that there are substantial differences in efficacy between drugs from different class 1 sub-groups when used in combination with amiodarone.

Amiodarone and flecainide made the most effective combination. Although this could be a general property of all class $1 \mathrm{c}$ drugs employed in combination with amiodarone, it is also possible that the result is a specific property of the combination of flecainide and amiodarone, a possibility which needs further evaluation. The study also shows, however, that whilst there was a significant drug response in a few tapes there is certainly no advantage from deliberately enhancing class 3 induced action potential prolongation with a class $1 \mathrm{a}$ drug and since class $1 \mathrm{~b}$ drugs tend to shorten this potentially deleterious effect they may make the safest combinations whilst still demonstrating a reasonable increase in efficacy.

The overall effect of combination therapy has to be viewed with some reservation since it is now well established that amiodarone increases the plasma levels of most class 1 drugs. $^{12}$ However, it seems unlikely that the marked increase in efficacy in this and other studies is purely due to a small increase in the plasma levels of the class 1 drug. In fact this study provides some evidence that the increased efficacy is not simply due to increased drug levels as two patients had previously been treated unsuccessfully with larger doses of the class 1 drug in question on its own (number 2 - flecainide $200 \mathrm{mg}$ twice daily and number 7 - disopyramide $300 \mathrm{mg}$ twice daily). It would have been interesting to compare plasma levels of the class 1 drugs with and without amiodarone but in view of the number of combinations employed, the length of time that would need to be allowed for amiodarone washout and the fact that several patients were unlikely to be able to be withdrawn from amiodarone therapy we decided that this was impractical. This question is, however, probably immaterial to the point at issue, of which class 1 sub-group contributes to the best combination, since it is likely that all the drugs employed in this study are similarly affected by amiodarone, ${ }^{4,12}$ which has been documented with certainty for class la drugs ${ }^{13}$ and lc drugs. ${ }^{14}$ 
Although the number of patients studied was small, we believe the results are of interest because the differences between treatments were very clear, whilst the results of consecutive 24 hour tapes during the same treatment periods were remarkably consistent. Furthermore, we have taken care to check that the results are not simply due to the addition of a new class 1 drug but are genuinely due to the combination. Small numbers for a study of this type are almost inevitable because it is difficult to obtain patients who have sufficiently severe symptoms to merit combination therapy, yet are able to stop treatments for the cross-over element of the trial.

In conclusion, whilst there is individual variation in responses to combination therapy, where empirical treatment for serious ventricular arrhythmias is necessary, our results suggest that the combination of amiodarone (class 3 ) and flecainide (class 1c) is likely

\section{References}

1. Vaughan-Williams, E. Selective restriction of ionic current by anti-arrhythmic drugs. In: Sleight, P., Jones, J.V. (eds) Scientific Foundations of Cardiology. Heinemann, London 1983, pp. 11-18.

2. Vaughan-Williams, E. Sub-groups of class 1 antiarrhythmic drugs. Eur Heart J 1984, 5: 96-98.

3. Singh, B. \& Nademanee, K. Control of cardiac arrhythmias by selective lengthening of repolarisation: theoretic considerations and clinical observations. Am Heart J 1985, 109: 421-430.

4. Marcus, F. Drug interactions with amiodarone. Am Heart J 1983, 106: 924-930.

5. Roden, D. \& Woosley, R. QT prolongation and arrhythmia suppression. Am Heart $J$ 1985, 109: 411-415.

6. Curry, P., Holt, P., Way, B., Awar, S. \& Holt, D. Intravenous amiodarone: an effective anti-arrhythmic agent. (Abstract) Br Heart J 1982, 47: 191- 192.

7. James, M., Papouchado, M. \& Jones, J.V. Combined therapy with disopyramide and amiodarone: a report of 11 cases. Int J Cardiol 1986, 13: 248-252.

8. Waleffe, A., Mary-Rubine, L., Legrand, V., Demoulin, J. \& Kulbertus, $\mathrm{H}$. Combined mexilitene and amiodarone treatment of refractory recurrent ventricular tachycardia. Am Heart J 1980, 100: 788-793. to be most effective and appears to be relatively safe, although we would recommend that shortly after starting such combinations the electrocardiogram is checked for toxic effects. Other class $1 \mathrm{c}$ drugs (such as flecainide, encainide, lorcainide and propaphenone) in combination with amiodarone may be equally effective but this possibility needs further evaluation. Combinations of amiodarone with mexilitene (class 1b) may be the safest by virtue of the QT shortening effect of class $1 \mathrm{lb}$ drugs, but the long term efficacy and safety of any of these combinations can only be established by further prospective studies of safety.

\section{Acknowledgements}

We wish to thank Drs Jordan and Russell Rees for allowing us to study patients under their care.
9. Lal, R., Quattromani, A., Smith, P., Kim, S.S., Schechtman, K. \& Ruffy, R. Amiodarone and flecainide combination treatment for severe ventricular arrhythmias. (Abstract) Circulation 1986, 74: 224.

10. Waleffe, A., Materne, P., El Allaf, D., Cartier, J. \& Kulbertus, H. Combined class 1 anti-arrhythmic agents and amiodarone for treatment of sustained recurrent ventricular tachycardia. In: Breitthardt, G. \& Loogen, F. (eds) New Aspects in the Medical Treatment of Tachyarrhythmias. Urban and Schwarzenberg, Munchen, 1983, pp. 186-191.

11. Morganroth, J., Michelson, E., Horrowitz, L., Josephson, M., Pearlman, A. \& Dunkman, B. Limitations of long term electrocardiographic monitoring to assess ventricular ectopic frequency. Circulation 1978, 58: 408-414.

12. Mason, J. Drug therapy: amiodarone. $N$ Engl J Med 1987, 316: 455-465.

13. Saal, A., Werner, J., Greene, H., Sears, G. \& Graham, E. Effect of amiodarone on serum quinidine and procainamide levels. Am J Cardiol 1984, 53: 1264-1267.

14. Shea, P., Lal, R., Kim, S.S., Schechtman, K. \& Ruffy, R. Flecainide and amiodarone interaction. $\mathrm{J} \mathrm{Am}$ Coll Cardiol 1986, 7: 1127-1130. 